\title{
25
}

\section{Eastern Asia: Sino-Tibetan linguistic history}

\author{
Randy J. LaPolla
}

The Sino-Tibetan language family enshrines the migratory histories of many East Asian populations, including the Chinese, Tibetans, and Burmese. Its history is intimately associated with Neolithic and Bronze Age developments in China itself, and today it is one of the major world language families in terms of population numbers.

The Sino-Tibetan (ST) languages are spoken throughout China and Myanmar/Burma and in parts of India, Thailand, Laos, and Vietnam (see Figures 25.1 and 33.1). The family includes as its two main branches the Sinitic languages (the Chinese "dialects") and the Tibeto-Burman (TB) languages. This major division is due to different paths of migration, and different types of language contact due to these and other population movements have created great diversity among the daughter languages of the family (see LaPolla 2001 for a more complete discussion).

The archeological and linguistic evidence suggests that the ancestors of the SinoTibetan speaking people lived in the central plains of the valley of the Huanghe (Yellow River). By at least $4500 \mathrm{BCE}$, some members of the original group began moving west, then to the south down through the Tibetan plateau or into the valleys to its east. The group that stayed in the central plains, as well as those who moved south and east in early historical times, eventually became the Sinitic speakers of today, while the group that moved southwest became the Tibeto-Burman speakers.

The movements in both directions were not single ones but consisted of larger or smaller waves, often into the same areas as earlier migrations. Government-encouraged migration was practiced in China as early as the 2 nd millennium всE, and has been practiced by all Chinese governments since then. There have also been massive migrations due to natural disasters, war, and the pull of new economic opportunities. The movement of the Sinitic speakers has almost never been to an area where there were

The Encyclopedia of Global Human Migration, Edited by Immanuel Ness.

(C) 2013 Blackwell Publishing Ltd. Published 2013 by Blackwell Publishing Ltd.

DOI: 10.1002/9781444351071.wbeghm825 


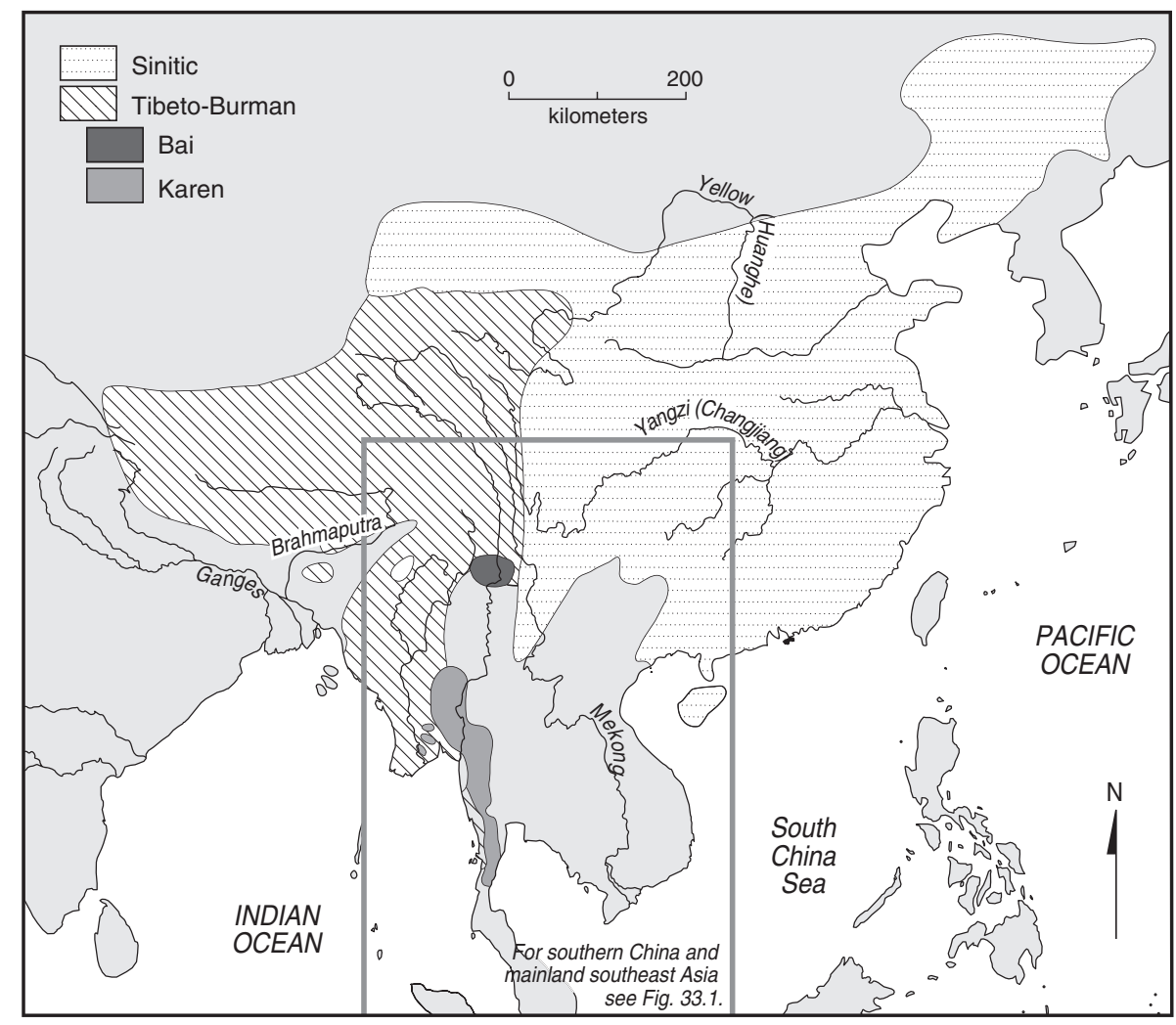

Figure 25.1 The distribution of the major components of the Sino-Tibetan language family, after Ruhlen (1987). For closer details of the situation in southern China and mainland Southeast Asia see Figure 33.1. Map production by Education and Multimedia Services, College of Asia and the Pacific, The Australian National University.

no people; migration almost always involved language contact, either with non-Sinitic languages or other Sinitic varieties, and very often in government-sponsored migrations there was purposeful mixing of peoples. As the Sinitic speakers moved into new areas they often absorbed the peoples already there or, in some cases, were absorbed themselves. From the linguistic evidence, it seems the earliest inhabitants of the southeastern coast of China spoke ancestral Austronesian-related languages, while those in the Yangzi basin and the inland south were speakers of ancestral Hmong-Mien and Tai-related languages. We find influences from these languages in the Sinitic varieties spoken in those areas.

Many of the movements were chain- or domino-like. For example, the migration of over two million non-Sinitic-speaking people from the northern steppes into the central plains in the 2nd and 3rd centuries CE caused at least three million Sinitic speakers to flee south. This not only affected the population of the north, but also of the south, as one out of every six people in the south after the migration was a displaced 
northerner. The movements were often so massive that they caused major shifts in the overall demographic and language distributions of the entire region. For example, in the 17th century, northeast and southwest China and the upper Yangzi contained only about 5 percent of the population of China, and 10 percent of the Mandarin Chinesespeaking population, but the subsequent movements into these areas from the middle Yangzi and north China were so massive that, by 1982, these three areas included onethird of China's population and about half of the Mandarin-speaking population (Lee \& Wong 1991: 55). In some areas, the movements have meant almost an entire displacement of the original population, with concomitant replacement of the original language. For example, since 1949 there has a been massive government-orchestrated movement of Han Chinese people into the minority areas of Inner Mongolia, Xinjiang, and Tibet. One result of this is that the population of Inner Mongolia is now less than 15 percent Mongolian, and less than 2 percent Mongolian in the capital, Huerhot.

Aside from these migrations of Sinitic speakers into other parts of China (or what later became part of China), there was also considerable influence from non-Sinitic speaking people moving particularly into northern China, where for more than half of the last thousand years the Chinese state was under the successive control of Mongolian and Manchu-speaking invaders. While many of these invaders assimilated into the Sinitic population, they also had an effect on the language of the north. Hashimoto (1976, 1980, 1986) has talked about this as "the Altaicization of Northern Chinese" (see also chapter 24), and has argued that a continuum of features from north to south reflects Altaic influence in the north and Tai/Hmong-Mien influence in the south. These features include fewer tones, less complex classifier systems and an inclusive/ exclusive first person plural pronoun distinction in the northern dialects, and more tones, more complex classifier systems and other features similar to the Tai and Hmong-Mien languages in the southern dialects. (Tai is the more general term for the large language family that includes Thai, the national language of Thailand.)

Turning to Tibeto-Burman (TB), some of the major migrations took place westwards from China into Tibet and then southwards into Nepal, Bhutan, and northern India. Others moved southwest down the river valleys along the eastern edge of the Tibetan plateau, passing through what has been called the "ethnic corridor" (Fei 1980) into Burma. There were also later minor movements into northern Thailand, Laos, and Vietnam. The two major TB migration paths described above have been responsible for the major split between the Bodish languages (Tibetan and its close relatives) and the rest of Tibeto-Burman. From the closeness of the Tibetan dialects, despite their present wide geographic spread, and from the fact that all dialects show some of the same borrowed features (such as non-TB words for "horse" and "seven"), there must have been contact with northern non-Tibeto-Burman languages before the spread of Tibetan. This spread was relatively rapid throughout Tibet, an area where there were few earlier inhabitants. TB migration into Nepal, Sikkim, and Bhutan was originally almost entirely from Tibet, and many of the TB languages there show a close relation to Tibetan.

Since the failed 1959 uprising against Chinese rule in Tibet a large number of Central Tibetan speakers have moved to Nepal and India. In Nepal, the TB languages are in contact with many non-TB languages, including the national language, Nepali, 
an Indo-Aryan language which has had a major impact on many of the TB languages. In Bhutan, where there were in the past only Southern Tibetan or Monpa speakers, there is now a large number of Nepali speakers. Many of the TB languages found in northeastern India and Bangladesh came from Burma to the east, but some came down from Tibet. They have been greatly affected by the cultures with which they have come into contact. For example, in Kashmir, Balti and Ladakhi are Western Tibetan dialects, but Balti is spoken in the (Pakistan-controlled) Baltistan area and the speakers of Balti are now Muslims and write their language with the Arabic script. Ladakhi is spoken in the Indian-controlled area of Kashmir, but the speakers are still more culturally Tibetan than Indian. In Manipur, there have been Meithei speakers for at least a thousand years, having moved there from Burma. Meithei is written with a Bengali-based Indic orthography and is heavily influenced by Indo-Aryan contact (Chelliah 1997). Aside from being spoken by about one million people, Meithei has become a lingua franca for many other ethnic groups in Manipur, and this has affected the linguistic form that it takes in each area where it is spoken, a situation we see also in the cases of Mandarin Chinese and Burmese.

The migration of TB speakers southwards into Burma must have started by the 1st century CE. Chinese records dating to the 4th century already talk of a civilized kingdom, known as Pyu, which controlled central and Upper Burma. The Pyu were TB speakers who had come down into Burma along the Irrawaddy valley. They adopted Theravadan Buddhism and a writing system during the 7th century from the Mon (Mon-Khmer speakers), who controlled Lower Burma and the Menam Chao Phraya valley, now part of Thailand. The Chin (Zo), another TB group, also came down into Burma sometime before the 9th century and established a kingdom in the Chindwin valley. In the 8th and 9th centuries, a kingdom called Nanzhao (previously spelt NanChao), located in what is now western Yunnan Province in southwest China, came to dominate Upper and most of Lower Burma. Nanzhao was ruled by Yi (Lolo; TB) speakers, but the population also included Bai (TB), other TB and Tai speakers. Sometime before the 8th century, the migration of the Karen, another TB group, down into Burma weakened the Pyu kingdom, and in 832 Nanzhao destroyed it. People related to the Burmese of today then moved down into Burma, beginning in the middle of the 9th century, from an area of Yunnan that was under the control of the Nanzhao kingdom. They settled from the Northern Shan states to the Kyanksè area south of Mandalay, and about $1000 \mathrm{CE}$ conquered the Mon to the south. As a result, the first Burmese kingdom, the Pagan kingdom, was founded in 1044. However, Mon culture was retained as the official Burmese court culture, and the Mon language (or Pali) was used for inscriptions. The Mon script also became the basis of the Burmese writing system. Much of southern Burma, such as the Irrawaddy delta and the region of Rangoon, was for most of its history part of a Mon kingdom, and the migration of the Burmese south into Mon territory led to a massive language shift of formerly Mon speakers to Burmese. A strong substratum influence of the Mon language on Burmese is still evident (Bradley 1980).

There are a number of Tibeto-Burman speakers in northern Thailand, such as the Akha, Lahu, Gong, Mpi, and Karen. Aside from the Karen, most have moved down from China within the past few hundred years. Northern Thailand was originally 
populated by Tai speakers, and the recent TB arrivals are now largely bilingual in Thai and their own languages. Their languages show quite a lot of Thai influence and even language shift.

In terms of large-scale areal contact, two large subgroupings can be distinguished within TB: the "Sino-sphere" and the "Indo-sphere" (Matisoff 1990). Features that we frequently find in languages in the Indo-sphere, but not in the Sino-sphere, include the development of retroflex stop consonants and post-head relative clauses of the Indic type (relative clauses are generally pre-head and without relative pronouns in Sino-Tibetan languages). In Sino-spheric languages we often find the development of tones and a movement toward a monosyllabic and isolating structure. Aside from this, there is also a broad tendency to have an iambic stress pattern in the south, most probably due to Mon-Khmer influence, as opposed to a more common trochaic pattern in the north.

SEE ALSO: 24 Northeastern and central Asia: “Altaic” linguistic history; 26 Eastern Asia: archaeology

\section{References}

Bradley, D. (1980) Phonological convergence between languages in contact: Mon-Khmer structural borrowing in Burmese. In B. R. Caron (ed.), Proceedings of the Sixth Annual Meeting of the Berkeley Linguistics Society. Berkeley: Berkeley Linguistics Society, pp. 259-267.

Chelliah, S. L. (1997) A Grammar of Meithei. Berlin: Mouton de Gruyter.

Fei Xiaotong (1980) Guanyu Woguo de minzu shibie wenti [On the problem of distinguishing nationalities in China]. Zhongguo Shehui Kexue 1, 158-174.

Hashimoto, M. J. (1976) Language diffusion on the Asian continent. Computational Analyses of Asian and African Languages 3, 49-63.

Hashimoto, M. J. (1980) Typography of phonotactics and suprasegmentals in languages of the East Asian continent. Computational Analysis of Asian and African Languages 13, 153-164.

Hashimoto, M. J. (1986) The Altaicization of Northern Chinese. In J. McCoy \& T. Light (eds.), Contributions to Sino-Tibetan Studies. Leiden: Brill, pp. 76-97.

LaPolla, R. J. (2001) The role of migration and language contact in the development of the Sino-Tibetan language family. In R. M. W. Dixon \& A. Y. Aikhenvald (eds.), Areal Diffusion and Genetic Inheritance: Case Studies in Language Change. Oxford: Oxford University Press, pp. 225-254.

Lee, J. \& Wong, B. (1991) Population movements in Qing China and their linguistic legacy. In W. S-Y. Wang (ed.), Languages and Dialects of China. JCL Monograph Series, No. 3. Berkeley: Project on Linguistic Analysis, pp. 52-77.

Matisoff, J. A. (1990) On meglocomparison. Language 66, 106-120.

Ruhlen, M. (1987) A Guide to the World's Languages, vol. 1. Stanford: Stanford University Press. 